\title{
Tedaviye Dirençli İmpetigo Herpetiformis'te Intravenöz İmmunglobulin Tedavisinin Etkinliği: Olgu Sunumu
}

\section{Successful use of Intravenous Immunoglobulin For Recalcitrant Impetigo Herpetiformis: Case Report}

\section{Hayriye Sarıcaoğlu, Sevgül Yıldırım, Hakan Ozan*, Emel Bülbül Bașkan, Kenan Aydoğan}

Uludağ Üniversitesi Tıp Fakültesi Deri ve Zührevi Hastalıklar Anabilim Dalı, *Kadın Doğum Hastalıkları Anabilim Dalı, Bursa, Türkiye

\section{Özet}

Impetigo herpetiformis $(\mathrm{IH})$, yüksek fetal morbidite ve mortaliteye sahip, bazen gebeliğin sonlandırılmasını gerektirebilen bir hastalıktır. Etkili olduğu belirtilen farklı tedavi seçenekleri bulunmaktadır. Yirmi üç yașında, psoriazis öyküsü olan 25 haftalık gebe olgu, ani bașlangıçlı jeneralize püstüler döküntülerle bașvurdu. Klinik bulgular ve histopatolojik değerlendirme ile IH tanısı konuldu. Sistemik prednizolon ( $2 \mathrm{mg} / \mathrm{kg} /$ gün) üç hafta süreyle uygulandı. Yanıt olmadığı için siklosporin A (3mg/kg/gün) ilave edildi. İki hafta siklosporin A ve sistemik prednizolon kombine kullanılmasına rağmen deri bulguları gerilemedi. Tedavilere ek olarak 30 . gebelik haftasında intravenöz immunglobulin (IVIG) $(0,3 \mathrm{gr} / \mathrm{kg} /$ gün, 6 gün) uygulaması ile deri belirtilerinde azalma gözlendi. 33. gebelik haftasında reaktivasyon olduğu için IVIG $(0,7 \mathrm{~g} / \mathrm{kg} /$ gün, 3 gün) tekrar verildi. Püstüler lezyonlar geriledi. 34. gebelik haftasında doğum yapan olgunun sağlıklı bir bebeği oldu. Bu olgu sunumu ile $\mathrm{IH}^{\prime}$ de gebeliğin devam etmesi ve fetusun sağlıklı gelișimini sağlaması amacıyla IVIG tedavisine dikkat çekilmektedir. (Türkderm 2012; 46: 104-6)

Anahtar Kelimeler: Impetigo herpetiformis, intravenöz immunglobulin

\section{Summary}

Impetigo herpetiformis $(\mathrm{IH})$, if left untreated, is associated with a high rate of perinatal morbidity and mortality and may lead to the decision of termination of pregnancy. There are various and effective therapeutic agents available for the treatment of the disease.

A 23-year-old woman with a history of plaque psoriasis presented with a sudden generalized pustular eruption on the 25th week of her first gestation. The diagnosis was made based on the clinical and histopathological findings. The patient was treated with systemic prednisolone $(2 \mathrm{mg} / \mathrm{kg} / \mathrm{d})$ first and, cyclosporine $\mathrm{A}(3 \mathrm{mg} / \mathrm{kg} / \mathrm{d})$ was added to the treatment after two weeks because prednisolone was not effective alone. The lesions did not regress despite four weeks of combined treatment with prednisolone and cyclosporine. Intravenous immunoglobuline (IVIG) $(0.3 \mathrm{~g} / \mathrm{kg} / \mathrm{d}, 6$ days) was added on the 30th week of gestation and resulted in regression of cutaneous rashes. On the 33 rd week of gestation, IVIG ( $0.7 \mathrm{~g} / \mathrm{kg} / \mathrm{d}, 3$ days) was repeated due to reactivation of pustules, and an improvement was observed. In this case report, we called attention to IVIG therapy in $\mathrm{IH}$, for having the pregnancy continued enough for the fetal maturation before the delivery. (Turkderm 2012; 46: 104-6)

Key Words: Impetigo herpetiformis, intravenous immunoglobuline

\section{Giriş}

Impetigo herpetiformis (iH), ilk olarak 1872 yılında Von Hebra tarafından gebeliğin spesifik dermatozu olarak tanımlanmıştır ${ }^{1}$. Günümüzde, IH'nin gebeliğin spesifik bir dermatozu mu yoksa jeneralize püstüler psoriazisin bir formu mu olduğuna dair tartışmalar devam etmektedir. Birçok yazar, IH'nin püstüler psoriazisin gebelikte endokrin değişikliklerle alevlenen jeneralize formu olduğunu ileri sürmektedir2. Bazı yazarlar ise; ï'de hipokalsemi olması ve gebelikte gözlenmesi sebebiyle psoriazisten farklı bir hastalık olarak yorumlamışlardır3,4

Impetigo herpetiformis, genellikle gebeliğin üçüncü trimestrinde ortaya çıkan yaygın püstüllerle karakterizedir. Çoğunlukla gebelikten sonra kaybolmakta, nadiren postpartum dönemde de devam edebilmektedir. Mortalite ve morbiditesinin yüksek

Yazışma Adresi/Address for Correspondence: Dr. Sevgül Yıldırım, Uludağ Üniversitesi Tıp Fakültesi, Dermatoloji Anabilim Dalı, Bursa, Türkiye Tel.: +90 2242950741 E-posta: drsevgul@gmail.com Geliş Tarihi/Received: 21.03.2010 Kabul Tarihi/Accepted: 27.01.2011

Türkderm-Deri Hastalıkları ve Frengi Arșivi Dergisi, Galenos Yayınevi tarafından basılmıștır.

Turkderm-Archives of the Turkish Dermatology and Venerology, published by Galenos Publishing. 
olması sebebiyle IH tanısı hızlı ve erken konulmalı, tedaviye hemen başlanmalıdır.

Tedavide sistemik kortikosteroidler ve siklosporin A gibi etkili olduğu belirtilen farkı tedavi seçenekleri bulunmaktadır 5 .

Intravenöz immunglobulin (IVIG), steroid ve diğer immunsupresif ajanlarda gözlenen yan etkilerin olmadığı güvenilir bir tedavi seçeneğidir. Birçok otoimmun ve inflamatuvar hastalıkta kullanılan immunsupresif bir ajan olarak tanımlanmıştır. Gebelerde, otoimmun trombositopenik purpura ve tekrarlayan düşük tedavisinde yaygın olarak kullanılması sebebiyle, iyi tolere edilebilen ve güvenilir bir tedavi seçeneği olarak görülmektedir6,7.

Bu olgu sunumuyla, tedaviye dirençli iH tanılı hastada IVIG'in tedavideki etkinliğine dikkat çekilerek, ïH'de bir tedavi seçeneği olarak gözönünde bulundurulabileceği düşünülmektedir.

\section{Olgu}

Haziran 2006'da, 23 yaşında, 25 haftalık ilk gebeliği olan hasta, ani başlangıçıı püstüler lezyonlar ile polikliniğimize başvurdu (Resim 1a). Altı ve dokuz yaşında iken plak psoriazis öyküsü olduğu öğrenildi.

Fleksör ve intertrijinöz alanlardan simetrik olarak başlayıp; yüze, bilateral alt ve üst ekstremitelere, sırt ve gövde ön yüze dağılım gösteren çok sayıda milimetrik püstüller ve vücudun $\% 80$ 'ini kaplayan, bazı alanlarda erode olmuş eritemli plaklar izlendi. Fizik muayene ve vital bulguları normal olarak değerlendirildi.

Laboratuvar bulgularında; lökositoz, anemi ve hipoalbuminemi saptandı. Kalsitonin, serum kalsiyum ve vitamin D düzeyleri normal sınırlardaydı. Deri biyopsisinde; akantotik epidermis, hiperkeratoz, fokal hipogranüloz, dermal papillalarda ödem ve mikrovezikülasyon vardı. Dermisin üst kesimlerinde, kapiller damarlar çevresinde monosit ve nötrofil infiltrasyonu izlendi. Direkt immunofloresan inceleme negatif idi. Klinik bulgular, dermatolojik muayene bulguları ve histopatolojik değerlendirme ile ïH tanısı konuldu.

Hastaya $2 \mathrm{mg} / \mathrm{kg} / \mathrm{gün}$ prednizolon başlandı. Üç hafta süreyle prednizolon uygulamasına rağmen deri lezyonlarında artış olduğu için 3 $\mathrm{mg} / \mathrm{kg} / \mathrm{gün}$ siklosporin A ilave edildi. Bir hafta sonra, tedaviye yanıt olmadığından siklosporin A dozu 4 mg/kg/güne çıkıldı.

iki hafta boyunca sistemik kortikosteroid ve siklosporin A kombine kullanımına rağmen hastanın döküntüleri gerilemedi. Bu nedenle,

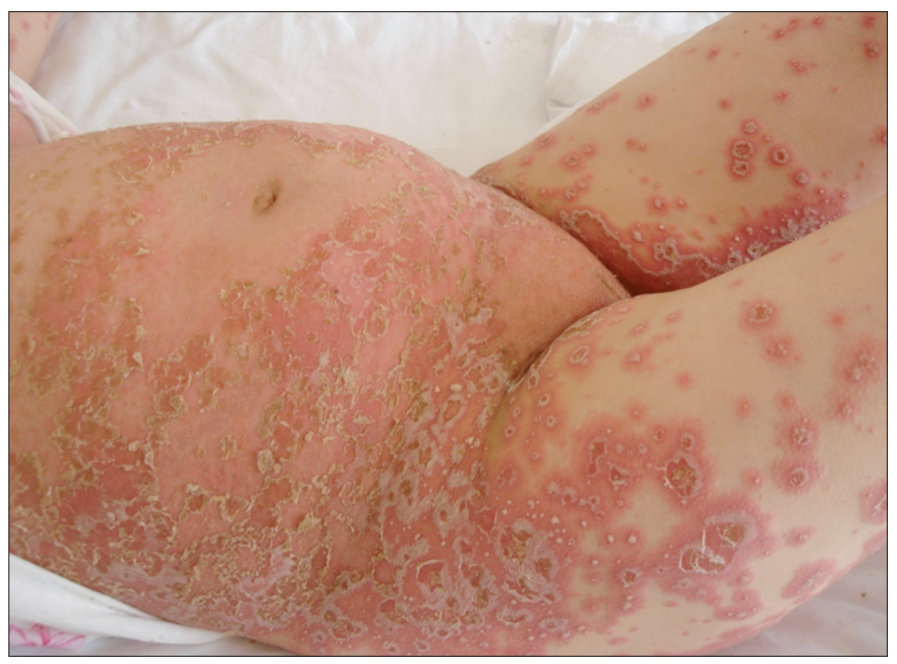

Resim 1a. Tüm vücutta jeneralize püstüler erupsiyon 30.gebelik haftasında, IVIG (0,3 gr/kg/gün, 6 gün) uygulandı. Hastanın deri belirtilerinde belirgin düzelme olduğu izlendi (Resim 1b). 33. gebelik haftasında, yeni püstül çıkışları gözlenmesi üzerine ikinci kür IVIG $(0,7$ $\mathrm{gr} / \mathrm{kg} / \mathrm{gün}$, 3 gün) verildi. IVIG uygulanması sonrasında püstüllerde gerileme olduğu gözlendi ve yeni lezyon çıkışı olmadı.

Fetus, obstetrik ultrason ile yakın takip edildi. 34. gebelik haftasında, oligohidramniyoz, doppler ultrasonda da azalmış amniotik volüm saptanmasından dolayı hastanın doğum yapması planlandı. Spontan vajinal doğumla, 34. gebelik haftasında, 1850 gr ağırlığında kız bebek doğdu. Bebek, prematürite, grade 2 intraventriküler hemoraji ve neonatal sepsis nedeniyle izlendi. Doğum sonrasında, olgunun döküntüleri gerilemeye başladı. Siklosporin ve prednizolon değişen dozlarda almaya devam etti.

Postpartum birinci ayda hastanın lezyonlarında reaktivasyon olduğundan siklosporin A (4 $\mathrm{mg} / \mathrm{kg} / g u ̈ n)$, prednizolon $(1,5$ $\mathrm{mg} / \mathrm{kg} / \mathrm{gün}$ ), metotreksat (10 mg/hf) ile kombine edildi. Ayrıca, IVIG $(0,4 \mathrm{gr} / \mathrm{kg} / \mathrm{gün}, 5 \mathrm{gün})$ verildi. 6 ay süreyle siklosporin ve metotreksat kombine kullanmaya devam eden hastanın remisyonda olması sebebiyle medikal tedavileri kesilerek izleme alındı.

2 yıl sonra, püstüllerde reaktivasyon olduğu için yeniden başvuran hastaya siklosporin A (4 mg/kg/gün) başlandı. 8 ay herhangi bir deri lezyonu gözlenmeyen hastanın siklosporin A tedavisi sonlandırıldı. Halen nüks olmadı ve şu anda 4 yaşında sağlıklı bir kızı var.

\section{Tartışma}

İmpetigo herpetiformis $(\mathrm{i} H)$, gebelikte görülen jeneralize püstüler lezyonlarla karakterize bir hastalıktır. Kuijpers ve ark.8, her iki hastalığın patogenezinde benzer mekanizmaların rol oynadığını ve IH'nin jeneralize püstüler psoriazisin bir varyantı olduğunu belirtmişlerdir. Psoriaziste, inflamasyon kaskadında rol oynayan proinflamatuvar Th-1 sitokinlerin yapımı artmaktadır. Bazı yazarlara göre, gebelikte Th-2 sitokinlerin düzeyi azalırken Th-1 sitokinler artmakta. Th-1 sitokinler psoriaziste alevlenmeye sebep olmaktadır'. Bunun dışında, i iH'de hipokalsemi olması ve gebelikte gözlenmesinden dolayı psoriazisten farklı bir hastalık olarak da yorumlanmıştır3,4.

i $\mathrm{H}^{\prime}$ de birçok tedavi seçeneği bulunmaktadır. Sistemik kortikosteroidler ilk tercih edilen geleneksel tedavidir ve iyi yanıt elde edilmektedir 1,10 . Sistemik kortikosteroidler gebelikte teratojenik değildir, fetusta konjenital

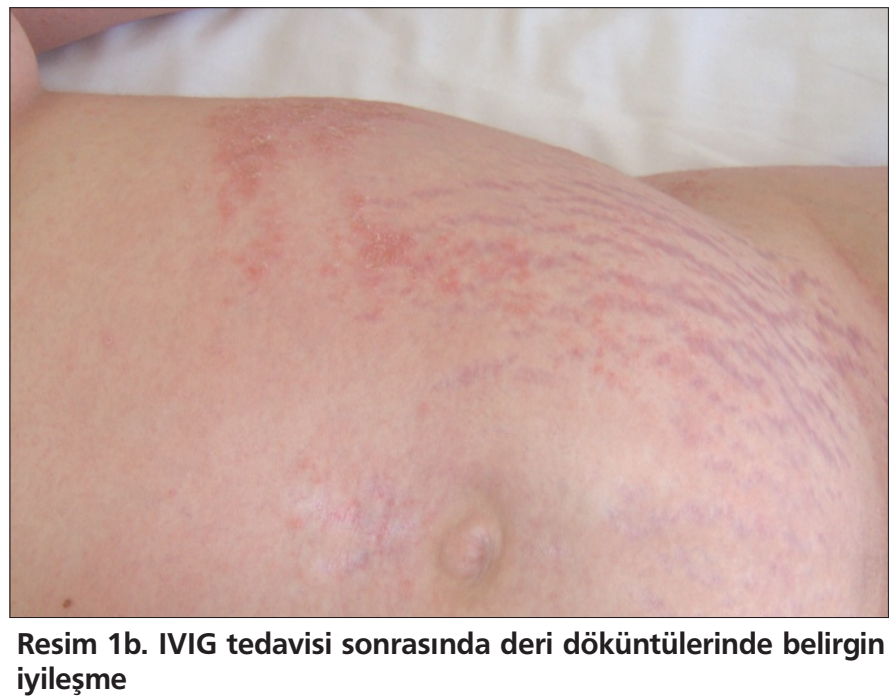


anomaliye neden olmazlar. Gebe olmayan kadınlarla aynı yan etki potansiyeline sahiptirler. Amniyotik erken membran rüptürü ve düşük doğum ağırlıklı bebek gözlenebilecek yan etkilerdir ${ }^{11}$.

Oral siklosporin, iH tedavisinde faydalı olduğu belirtilen ikinci tedavi seçeneğidir1,5,10. Doza bağımlı olarak plasental membrandan geçebildiğinden gebelikte " $\mathrm{C}$ " kategorisindedir. Lamarque ve ark.12 renal transplantlı, siklosporin kullanan 629 gebe hastadaki gözlemlerinde siklosporinle herhangi bir teratojenik etkiye rastlamadıklarını bildirmişlerdir. Guide ve ark.'da, intrauterin yaşamda siklosporine maruz kalmış olan çocukların renal fonksiyonlarının normal olduğunu gözlemlemişlerdir13. Bar ve ark.'nın yaptığı bir meta- analiz çalışmasında, siklosporinin erken membran rüptürü ile ilişkili olabileceği, bu sebeple gebelik süresince yakın serum kreatinin takibi ve fetusun ultrasonografik değerlendirilmesi gerektiği vurgulanmıştır ${ }^{14}$. Illaçlarla ilgili bu yan etkilerin dışında, i H'de erken doğum, plasental yetmezlik, erken membran rüptürü gibi komplikasyonlar gözlenebilmektedir.

Olgumuzda, yapılan seri ultrasonografik incelemeler sırasında tespit edilen oligohidramniyoz, i H'de görülen bir komplikasyon olarak değerlendirilmiştir. Grade 2 intraventriküler hemoraji, düşük doğum ağırığı ve neonatal sepsisin de prematürite ile ilişkili olduğu düşünülmüştür. Fakat, gebelikte sistemik kortikosteroid kullanımına sekonder erken membran rüptürü ve düşük doğum ağırlığı görülebileceği, siklosporin kullanımına sekonder de erken membran rüptürü olabileceği unutulmamalıdır.

Hastada, prednizolon ve siklosporinin kombine kullanımına rağmen yeni lezyon çıkışları olması üzerine alternatif bir tedaviye intiyaç duyulmuştur.

Psoriazis, Th1 hücrelerinin rol oynadığı otoimmun bir hastalıktır. Bazı yazarlar bu temelden yola çıkarak IVIG tedavisinin psoriaziste uygulanabileceğini öne sürmüşlerdir. IVIG'in, TNF- $\alpha$ gibi sitokinlerin oluşumunu inhibe ederek psoriaziste uygulanabileceği öne sürülmüştür6-15. Gebelikte de çeşitli otoimmun hastalıklarda güvenle kullanılabilmesi ve iyi tolere edilmesi sebebiyle de teratojenik olmadığı bilinmektedir7. Gurmin ve ark.15, psoriazis ve psoriatik artropati tanısı olan üç hastada IVIG uygulamışlar ve hastaların psoriatik lezyonlarında ve eklem ağılarında iyileşme gözlemlemişlerdir. 2006 yılında Taguchi ve ark., psoriazis vulgaris tanısı ile izlenen aynı zamanda kronik inflamatuvar demiyelinizan polinöropatisi (CIDP) olan bir hastada IVIG uygulamışlardır ${ }^{16}$. Tedavi sonrasında CIDP semptomlarında düzelmenin yanı sıra psoriatik plaklarda da dramatik iyileşme olduğunu bildirmişlerdir. Impetigo herpetiformis'in de psoriazisin gebelikte görülen bir varyantı olduğu düşünülerek, bizim olgumuzda da sistemik prednizolon ve siklosporin kullanımına rağmen yeni lezyon çıkışının devam etmesi sebebi ile gebelikte kullanımı güvenli olan IVIG tedavisi uygulanmıştır.
IVIG uygulaması sonrasında da deri lezyonlarının tamamen yok olduğu ve gebelik süresince annede ve fetusta herhangi bir komplikasyona neden olmadığı gözlenmiştir. Şu anda da anne ve çocuğu sağlıklıdır.

Mevcut bilgilerimize göre IVIG, IH tedavisinde ilk olarak bizim olgumuzda kullanılmıştır. Bu olgu vesilesiyle, IH'de gebeliğin devamı, uygulanan ilaçlarla yan etki gözlenen ve geleneksel tedavilere dirençli olgularda alternatif tedavi seçeneği olarak önerilebileceğini düşünüyoruz.

\section{Kaynaklar}

1. Hebra F: Ueber einzine wahrend s wangers chaft, dens wacherbette unde bei uterinal. Krankheiten der Frauen zu beobchtende Hautkrank-heiten. Wien Med Wochenschr 1872;48:1197-202.

2. Breier-Maly J, Ortel B, Breier F, Schmidt JB, Hönigsmann H: Generalized pustular psoriasis of pregnancy (impetigo herpetiformis). Dermatology 1999;198:61-4.

3. Lotem $M$, Katzenelson $V$, Rotem $A$, Hod $M$, Sandbank $M$ : Impetigo herpetiformis: a variant of pustular psoriasis or a separate entity? J Am Acad Dermatol 1989;20:338-41.

4. Pierard GE, Pierard-Franchimont C, de la Brassinne M: Impetigo herpetiformis and pustular psoriasis during pregnancy. Am J Dermatopathol 1983;5:215-20

5. Imai $\mathrm{N}$, Watanabe $\mathrm{R}$, Fujiwara $\mathrm{H}$, Ito $\mathrm{M}$, Nakamura A: Successful treatment of Impetigo herpetiformis with oral cyclosporine during pregnancy. Arch Dermatol 2002;138:128-29.

6. Jolles S, Hughes J: Use of IVIG in the treatment of atopic dermatitis, urticaria, scleromyxedema, pyoderma gangrenosum, psoriasis and pretibial myxedema. International Immunopharmacology 2006;6:579-91.

7. Hutton $B$, Sharma R, Fergusson $D$, et al: Use of ntravenous immunoglobulin for treatment of reccurrent miscarriage: a systemic review. An International Journal of Obstetrics and Gynaecology 2007;114:134-42.

8. Kuijpers ALA, Schalkwijk j, Rulo HFC, et al: Extremely low levels of epidermal skin-derived antileucoproteinase/ elafin in a patient with impetigo herpetiformis. Br J Dermatol 1997;137:123-29.

9. Raychaudhuri SP, Navare T, Gross J, et al: Clinical course of psoriasis during pregnancy. Int J Dermatol 2003;42:518-20.

10. Edmonds EVJ, Morris SD, Short K, Bewley SJ, Eady RAJ: Pustular psoriasis of pregnancy treated with ciclosporin and high dose prednisolone. Clinical and Experimental Dermatology 2005;30:707-26.

11. Lockshin MD, Sammaritano LR: Corticosteroids during pregnancy. Scand J Rheumatol Suppl 1998;107:136-8.

12. Lamarque $V$, Leleu W, Monka C, Krupp P: Analysis of 629 pregnancy outcomers in renal transplant recipients with Sandimmun. Transplant Proc 1997:29:2480.

13. Giudice PL, Dubourg L, Hadj-Aïssa A, et al: Renal function of children exposed to cyclosporine in utero. Nephrol Dial Transplant 2000;15:1575-79.

14. Bar Oz B, Hackman R, Einarson T, Koren G: Pregnancy outcome after cyclosporine therapy during pregnancy: a met-analysis. Transplantation 2001;71:1051-55.

15. Gurmin V, Mediwake R, Fernando $M$, et al: Psoriasis: response to high-dose intravenous immunoglobulinin three patients. Br J Dermatol 2002;147;554-57.

16. Taguchi Y, Takashima S, Yoshida S, et al: Psoriasis improved by intravenous immunoglobulin therapy. Intern Med 2006;45;879-80. 